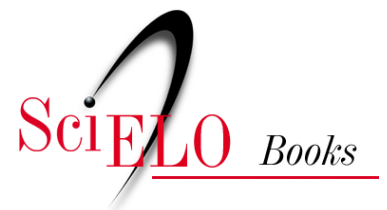

\title{
EDUFU
}

\section{A escrita do relatório aprendizagem e profissionalização em cursos técnicos de nível médio}

\author{
Léa Dutra Costa
}

\section{SciELO Books / SciELO Livros / SciELO Libros}

COSTA, L.D. A escrita do relatório: aprendizagem e profissionalização em cursos técnicos de nível médio. In: AGUSTINI, C., and ERNESTO, B., eds. Incursões na escrita acadêmico-universitária: letramento, discurso, enunciação [online]. Uberlândia: EDUFU, 2017, pp. 173-192. ISBN: 978-65-86084-26-9.

https://doi.org/10.7476/9786586084269.0011.

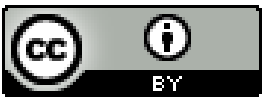

All the contents of this work, except where otherwise noted, is licensed under a Creative Commons Attribution 4.0 International license.

Todo o conteúdo deste trabalho, exceto quando houver ressalva, é publicado sob a licença Creative Commons Atribição 4.0. 


\section{A escrita do relatório: aprendizagem e profissionalização em cursos técnicos de nível médio}

Léa Dutra Costa

A recente expansão da Educação Profissional em todo o país tem chamado ainda mais a atenção para a formação de profissionais de nível médio e incrementado o estudo dos gêneros usados nesse nível de formação. Além disso, é importante considerar que um dos impactos relevantes do Interacionismo Sócio-Discursivo está na ampliação de pesquisas voltadas para os gêneros acadêmicos e entre estes se encontra o relatório. $\mathrm{Na}$ lembrança de muitos profissionais, está o relatório a remexer-lhes a aprendizagem de conteúdos científicos e tecnológicos de tal maneira que a assunção ao discurso acadêmico já se inicia com a escrita de relatórios em cursos técnicos e impactará tanto a atuação no mercado de trabalho como a formação no ensino superior.

Autores consultados sobre a escrita no contexto de ensino de ciências afirmam que ela estabelece uma relação positiva com as capacidades de análise e síntese e com o protagonismo juvenil na vida escolar e social dos aprendizes. Klein e Aller (1998, p.26, apud Souza e Arroio, 2009) asseguram que a escrita é "um modo único de aprendizagem, não apenas valioso, não simplesmente especial, mas único". Especialistas em letramento científico, esses autores veem as "formas tradicionais prescritivas" como um recurso didático-pedagógico capaz 


\section{Léa Dutra Costa}

de propiciar a aprendizagem. Apesar dessa valorização, constata-se, em boa parte das grades curriculares das licenciaturas e bacharelados afins à área das Ciências da Natureza, Matemática e suas Tecnologias, a ausência de disciplinas especificamente voltadas para o ensino da linguagem científica. Essa ausência, muitas vezes suprida pela iniciativa dos professores, pode implicar prejuízo na formação do profissional docente e discente.

Entre os muitos linguistas que se dedicam à aprendizagem e ao papel da escrita no ensino de Língua Portuguesa, Baltar (2004) salienta a escrita como ferramenta capaz de desencadear processos cognitivos, favorecendo a neutralização de fatores conjunturais e a construção de um modelo teórico estrutural do mundo por ser uma forma privilegiada de conferir visibilidade e viabilidade dos pensamentos. Tal perspectiva linguística vai exatamente ao encontro das ideias sobre o papel da escrita como atividade na formação de técnicos, que, aliás, requer conhecimentos científicos e tecnológicos sólidos.

Neste artigo, pretende-se então impulsionar as pesquisas sobre o referido gênero, tendo-se em vista que, na sua utilização como recurso mediador de aprendizagem, encontra-se a proposição de que os relatórios são um instrumento eficaz de ensino-aprendizagem e próprio da atividade profissional do técnico. Objetiva-se descrever e analisar aspectos pedagógicos e linguísticos que podem ser evidenciados a partir da demanda por esse gênero, considerando a relação entre o momento de evolução do desenvolvimento humano de jovens recem-egressos do ensino fundamental e futuros profissionais técnicos e a sua competência discursiva (Baltar, 2004).

Serão focalizados relatórios produzidos por aprendizes do $1^{\mathrm{O}}$ ano do Ensino Médio, após a realização de atividades práticas em laboratório, oficina ou campo, com textos que serão aqui denominados "relatórios de experimento - RE ". A observação empírica do uso de variados modelos de relatório no ensino médio e superior, já realizada por esta autora, os estudos e pesquisas sobre gêneros à luz do Interacionismo SócioDiscursivo e, em especial, as pesquisas a respeito de relatórios e de relatos de estágio na graduação (Gregório, 2003; Silva 2013), contribuíram para que fosse formulada a hipótese de que a demanda por RE, assemelha-se àquela apresentada aos alunos do ensino superior. 


\section{Fundamentação teórica}

A fim de fundamentar adequadamente a demanda por relatórios em cursos técnicos, parte-se do princípio de que se deve buscar uma articulação entre aspectos pedagógicos e linguísticos. Ambos, neste artigo, serão abordados pela perspectiva interacionista.

De um ponto de vista pedagógico, há que se levar em conta a influência e a inter-relação de fatores biológicos, psicossociais e escolares no processo de ensino-aprendizagem (Fernandez, 1991; Pain,1992), que se intensificam no Ensino Médio, cursado, regularmente, na adolescência.

Segundo Knobel (2007), a adolescência é uma fase de instabilidade, cheia de contradições, confusões, ambivalências; é uma fase que vem acompanhada por atritos com o meio familiar e social e por sentimentos de perdas e lutos. Em outras palavras, o adolescente é uma pessoa que vive alterações hormonais e cresce deixando um corpo e comportamentos infantis para trás; uma pessoa que modifica suas relações afetivas, seus interesses e crenças; que enfrenta novas propostas pedagógicas, novos currículos e contratos didáticos, entre tantos outros acontecimentos importantes para o desenvolvimento humano pleno. Para as finalidades deste artigo, é suficiente ressaltar que o adolescente é uma pessoa que, além de embrulhar-se nesses elementos, ou de ser embrulhado por eles, ainda tem que escolher uma profissão (algo bastante difícil até para muitos adultos). Ele também deve, necessariamente, aprender conteúdos científicos e tecnológicos especializados junto a conteúdos do Ensino Médio.

A influência desses elementos é um aspecto do emprego de relatórios na aprendizagem que deve ser considerada linguisticamente, pois, como afirma Bakhtin (2003), há, entre os gêneros, aqueles que são pouco afeitos à expressão de uma identidade e de uma subjetividade e que têm conteúdo temático, estrutura composicional e estilo fixos; aqueles gêneros que são caracterizados por serem menos flexíveis e, por isso, mais estáveis. Tais singularidades fazem dos relatórios um desses gêneros que, a princípio, podem ser vistos como incompatíveis com a adolescência.

Nesse sentido, é essencial considerar que Schneuwly e Dolz (2004) constatam um momento de ruptura no processo de escolarização e aprendizagem da comunidade franco-suíça, o qual ocorre, segundo eles, na passagem do ensino fundamental para o ensino médio, em termos dos níveis 


\section{Léa Dutra Costa}

educacionais brasileiros. Tal acontecimento, de natureza psicopedagógica, pode ser verificado também na educação brasileira, em especial, por professores do $1^{\underline{0}}$ ano do Ensino Médio, série em que diversos problemas de desempenho originam-se nas transformações físicas e psicossociais próprias da adolescência.

Em estudo realizado por Costa e Lima (2010) sobre fatores sociais, afetivos e escolares correlacionados ao baixo desempenho em Matemática, na $1^{\text {a }}$ série em cursos técnicos, as autoras concluem que pequenas diferenças entre as práticas de avaliação de desempenho de um nível de ensino e outro podem ser capazes de determinar retenções e índices de evasão escolar significativos. Se, apenas no ensino médio, essa ruptura já acarreta sérias consequências, o que dizer quando a ele simultaneamente se agregam disciplinas técnicas junto à escolha de uma profissão?

De um ponto de vista linguístico-discursivo, a definição bakhtineana como formas relativamente estáveis no tempo e no espaço, compostas por um conteúdo temático, uma estrutura composicional e um estilo, pertinentes a uma esfera social, subdividindo- se em gêneros primários (diálogos e textos mais típicos da oralidade) e gêneros secundários (romances e gêneros mais característicos do mundo da escrita), é interessante para, de certa forma, entender a adoção do RE. Ele tem a atemporalidade da escrita, é altamente estável e trata de conhecimentos científicos realizados a partir de experimentos; seu estilo é convencional (cabeçalho, introdução, objetivos, procedimentos e métodos, apresentação e discussão de resultados e conclusão ou considerações finais; no RE, privilegia-se o uso da $3^{\mathrm{a}}$ pessoa e a presença de outras linguagens não verbais). É também próprio de uma esfera social (cursos técnicos, seus professores e alunos). Desse modo, sendo caracterizado como uma forma prescritiva, em linguagem científica, objetiva, precisa e impessoal, acredita-se que o gênero propicia boas condições para que o cidadão desenvolva o ensino de Ciências da Natureza, Matemática e suas Tecnologias como:

um aprendizado útil à vida e ao trabalho [...] de percepção evolutiva da vida, do planeta e do cosmos, enfim, um aprendizado com caráter prático e crítico e uma participação no romance da cultura científica, ingrediente essencial da aventura humana (LDB-MEC, 1996, p.4-7, grifos nossos). 
A escrita do relatório: aprendizagem e profissionalização em cursos técnicos...

Discursivamente, ainda há que se considerar, nesse contexto de ensino, a visão de Bazerman (2005), segundo a qual, entre as características dos gêneros está o seu potencial de fornecer aos membros de uma comunidade as orientações comunicativas e comportamentais das quais devem se dispor para bem se situarem em determinada esfera social. Trata-se, portanto, de ver o emprego por relatórios de experimentos como uma prática de letramento que

pressupõe sujeitos ou grupos sociais que dominam o uso da leitura e da escrita, tendo por isso as condições necessárias para uma participação ativa e competente em situações nas quais práticas de leitura e de escrita têm uma função essencial, do que resulta um certo estado ou condição de inserção em uma sociedade letrada (Soares, 1986, p.34).

Os alunos têm o parâmetro das notas obtidas nos relatórios para lhes orientar a conduta; têm, direta ou indiretamente, indicadores a partir do seu desempenho como um sujeito letrado, ou em letramento em ciências ou até mesmo nada disso. Certos alunos podem concluir que nada sabem nem do ponto de vista científico nem do ponto de vista comunicativo. Quando a produção do gênero faz parte de um sistema de avaliação de desempenho quantitativo, essa impressão de fracasso é bastante comum.

Assim, é importante observar que a escrita de um RE começa e é avaliada, tão logo tem início o ano letivo, ou seja, não é um aprendizado que vai sendo construído ao longo de uma sequência didática. No decorrer do ano, os alunos vão-se adaptando a seu novo contexto de aprendizagem e, na medida em que isso acontece, ocorre também o aprimoramento dos textos produzidos, como mostrado adiante. É relevante perceber, assim, a evolução da competência discursiva dos alunos como é entendida por Baltar (2004): o desenvolvimento de uma capacidade de

mobilizar recursos de vários níveis para, através da produção e recepção de um texto empírico, interagir sócio-discursivamente. Mobilizar esses recursos implica o domínio, o conhecimento e a escolha dos gêneros textuais presentes em um ambiente discursivo; implica o domínio das estruturas estáveis que compõem esses gêneros; implica o conhecimento dos mecanismos de textualização e de enunciação; implica a capacidade de mobilizar conteúdos temáticos tendo em vista o ambiente discursivo 
e as posições de seus interlocutores; por fim implica a capacidade de transferir saberes oriundos de um trabalho de ensino-aprendizagem num ambiente escolar para poder transitar em um ambiente discursivo (Baltar, 2004, p.19).

Nas interações com o professor, com os colegas de turma e com o objeto de estudo, na repetição continuada da mesma atividade de produção de relatórios, os alunos vão-se apropriando naturalmente do gênero; vão mobilizando recursos, dominando estruturas genéricas, colocando em cheque a necessidade de ser o gênero um objeto ensinável. Porém, as dificuldades, que podem surgir da combinação da escrita de um gênero específico com um saber científico, devem ser bem pensadas. Escrever para aprender ciências é uma orientação pedagógica que suscita questões delicadas no que se refere à relação de completude que deve existir entre o conteúdo temático, a estrutura composicional e o estilo próprios de todo gênero, principalmente, quando - grosso modo - ocorre o erro no âmbito do conhecimento científico e tecnológico.

Na análise de relatórios de estágio feita por Silva (2013), encontrase a proposta de que eles sejam vistos como um gênero capaz de promover a prática de uma escrita reflexiva em que o aluno deve: associar a atividade prática ao conteúdo teórico em estudo; produzir textos escritos de acordo com os discursos de cada área ou professor e ter cuidado em escolher a palavra certa no lugar certo; convergência de várias qualidades, utilidades e habilidades, entre essas, a habilidade de articular o experimento com conhecimentos teóricos trabalhados em sala de aula. 0 mesmo ocorre com o RE, que, para os professores, funciona como instrumento mediador ${ }^{1}$ de aprendizagem. Isso significa que eles, ao atribuírem ao relatório à capacidade de colocar-se entre o aluno e o saber científico como uma ferramenta, têm em mente que seus alunos também associam o conteúdo teórico à atividade realizada no laboratório em linguagem científica.

Além desse aspecto, Silva (2013) constata o quanto é variada a demanda por textos escritos na graduação e o quanto fica a desejar o ensino da escrita acadêmica, pois, muitas vezes, os professores esperam tacitamente que os alunos saibam de antemão determinados conheci-

\footnotetext{
${ }^{1}$ Neste artigo, segue-se o conceito vygotskiano para instrumento mediador, vale dizer que o relatório seria um elo intermediário entre o aluno e o conhecimento científico disponível no experimento realizado em laboratório.
} 
mentos que eles (professores) têm, o que nem sempre acontece. Esse quadro de expectativa comum na graduação também é recorrente no ensino médio profissionalizante.

Com relação a isso, é pertinente considerar que o domínio da escrita e da linguagem científica são essenciais para a construção de conhecimentos na área. Torna-se por isso, igualmente essencial, considerar o que Bawarshi e Reiff afirmam a esse respeito:

estudantes com mais dificuldade para escrever [...] 'foram aqueles que ainda não tinham aprendido a traduzir as exigências do professor para determinado gênero em suas próprias palavras' [...] Um dos resultados é que o conhecimento tácito do professor torna difícil articular claramente as expectativas explícitas para o gênero (Bawarshi; Reiff, 2013, p.151).

A partir de Schneuwly e Dolz (2004), é possível pressupor que o RE teria condições de torna-se um "mega instrumento de aprendizagem", desde que devidamente apropriado pelos alunos. Além de todas as ações/ habilidades envolvidas no processo de transformação de uma linguagem que expresse a construção de um saber em texto, é válido considerar que a linguagem de um relatório de experimento é tipicamente multimodal. Como mencionado antes, os alunos devem apresentar em seus textos tabelas, gráficos, figuras, entre outros gêneros que os professores, muitas vezes, esperam que seus alunos já dominem.

\section{Metodologia}

Como este estudo desenvolveu-se a partir da pesquisa de doutorado da autora, seu corpus foi constituído por uma pequena mostra de relatórios produzida por alunos do 1ํano, de uma só disciplina da área das Ciências da Natureza, Matemática e suas Tecnologias, em uma unidade de ensino profissional vinculada a uma universidade pública. Também compuseram o corpus oito entrevistas com os estudantes em 2012 e 2013. Tal disciplina faz parte da grade curricular de todos os cursos oferecidos pela escola, que congrega uma pluralidade significativa de concepções e práticas pedagógicas.

Em uma aula semanal de 100 minutos, de forma alternada, os alunos executavam um experimento e escreviam o relatório correspondente, seguindo um roteiro escrito de orientações, entregue pelo professor para 
a finalidade de elaboração do texto. Além desse material, os alunos foram acompanhados pelo docente, que realizava intervenções na escrita dos alunos quando percebia a presença de erro. Tais intervenções ocorriam sob a forma de questionamentos conforme orientam as metodologias baseadas em resolução de problema. Foram coletados os relatórios correspondentes ao primeiro, segundo e último experimento realizados no $1^{\circ}$ trimestre de 2014 por duas turmas de $1^{\circ}$ ano. Os textos do primeiro experimento foram elaborados sem a participação ou intervenção do professor, que apenas pediu às turmas que escrevessem um relatório do experimento que haviam acabado de fazer.

Tanto o experimento quanto o relatório foram feitos no $1^{\mathrm{o}}$ dia de aula. Nessa situação, os estudantes, individualmente, valeram-se somente dos seus conhecimentos prévios sobre o gênero em uma esfera social, na qual se encontram superpostos o saber escolar e o saber científico. Tais textos foram identificados como "relatório de experimento produzido sem a intervenção do professor" e identificados como "R1".

Para o segundo experimento, os mesmos alunos contaram com o professor na leitura e compreensão de um roteiro escrito que lhes fora entregue no início da aula e que versava sobre o conteúdo e forma de um RE realizado em laboratório. Nele estavam previstas e descritas seis sessões: Introdução, Objetivos, Justificativa, Procedimentos e Métodos, Apresentação e Análise de Resultados e Conclusão ou Considerações Finais, além do Cabeçalho. 0 professor também os acompanhou durante a escrita, atendendolhes às solicitações. Esses textos receberam a denominação de "relatório de experimento após a primeira intervenção do professor" e foram representados pela sigla "R2". Daí até o final do trimestre, todos os alunos escreveram seus relatórios contando com esse roteiro, com o acompanhamento efetivo do professor em sala de aula e com a participação de colegas de grupo. Ao último conjunto de relatórios coletados, deu-se o nome de "último relatório de experimento produzido com a intervenção do professor - R3".

Foram coletados 25 relatórios de experimento sem a intervenção do professor (R1), 19 relatórios após a primeira intervenção (R2) e 14 R3, totalizando 48 relatórios ao final do trimestre, dos quais resultaram 13 sequências compostas por R1, R2 e R3 de cada aluno. A faixa etária do grupo pesquisado foi de 14 a 16 anos e a bagagem de conhecimentos científicos e linguísticos acumulados ao longo da vida escolar era bem variada. Os dados coletados foram analisados a partir da proposta 
de transformação da linguagem em textos orais e escritos, elaborada por Nascimento e Cristovão (2011), embasada na teoria de Bronckart (2003). De acordo com essa proposta, o processo de transformação deve considerar dois níveis de análise: um relativo aos fatos físicos e sociais observáveis no contexto de comunicação - nível sociológico; e o outro, aos fatos relativos à leitura de explícitos e implícitos no texto (fatos do contexto, que constituem o nível psicológico).

O primeiro nível citado é constituído por um conjunto de operações de contextualização (lugar social do agente, finalidade da atividade, relações entre parceiros, os interlocutores, o momento e o lugar da enunciação e por macroestruturas semânticas relacionadas ao conteúdo referencial e disponíveis na memória de cada aluno participante). Esse conjunto de operações forma uma base de orientação para a adoção de um modelo de gênero pertinente para a situação de ação. Já o segundo nível contempla as operações de textualização (operações de ancoragem textual, de referencialidade, de planificação e operações de estratégias linguísticas e discursivas). Da passagem por esses dois níveis resulta um produto final, que as autoras identificam como "texto" e que a autora deste artigo considera ser mais adequado chamar de gênero textual.

Para este artigo, foram considerados apenas os dados do "relatório de experimento produzido sem a intervenção do professor" (R1) e do "relatório de experimento após a primeira intervenção do professor" (R2) de um só aluno.

\section{Apresentação e análise de resultados}

Sob um ponto de vista quantitativo, segundo estimativa inicial, um só aluno de curso técnico regular produz, ao longo dos dois primeiros anos de sua formação, cerca de 60 relatórios. Trata-se de um volume bastante considerável para jovens egressos do ensino fundamental, tal como se pode conferir pelos dados mostrados a seguir.

(1) Número de disciplinas no $1^{\circ}$ ano: duas (Ciências da Natureza: 14 a 16 relatórios anualmente; 6 a 8 relatórios $=20$ a 22 em média).

(2) Número de disciplinas no 20 ano: quatro (Ciências da Natureza e Ciências Exatas: Ciências da Natureza: 28; Ciências Exatas: 20 = 48 em média).

(1) Número de disciplinas com demanda esporádica: indeterminado. 
Conforme esses dados, a média de relatórios produzidos por ano dobra - do primeiro para o segundo ano - de 20 a 22 para 48. Esse fato, quando associado ao $2^{\circ}$ ano, faz pressupor que quanto mais próximo do último ano, mais relatórios podem ser produzidos, ou seja, tanto mais relatórios produzidos quanto mais próximos os estudantes estariam de uma certificação profissional. Em outras palavras, os alunos estariam sendo bem ou bastante preparados para a produção de um gênero característico da esfera de trabalho da qual passariam a fazer parte e para o qual não lhes seria necessário ensino na graduação.

Ainda que a escrit(ur)a possa ser tão dialógica quanto à oralidade, pois alguém (o professor) selecionou algo para outro alguém (os alunos) com quem deseja se comunicar (Antunes, 2010), como instrumento de aprendizagem, a escrita dependerá não só das interações estabelecidas com o outro e o contexto como tão também estará na dependência da relação que cada aluno tem com ela. Um mau desempenho na escrita pode significar ou acarretar um mau desempenho na aprendizagem dos conteúdos científicos; dependerá ainda da relação que o professor tem com a leitura e a escrita, o que poderá ser inferido dos dados e da análise qualitativa que se seguem.

A seguir apresentam-se os relatórios R1 e R2, que serão, logo em seguida, analisados à luz da proposta de transformação da linguagem em textos orais e escritos, elaboradas por Nascimento e Cristovão (2011).

Quadro 1 - Relatório de experimento produzido sem a intervenção do professor (R1).

AAMB27/02/14

Relatório - medida de tempo de reação a estímulos externos

Na aula passada estudamos a medida de tempo de reação a estímulos externos. Para calcular esse tempo fizemos uma roda, e uma pessoa com um cronômetro e essa pessoa aperta a mão de uma pessoa e inicia o cronômetro o cronômetro e cada pessoa começa a apertar a mão da pessoa seguinte até que chegue na pessoa que estava com cronômetro, ai então ela pra o cronômetro.

Como nem sempre dará o mesmo tempo, repetimos essa atividade por 10 vezes e registramos cada valor e tiramos uma média dos tempos obtidos e depois dividimos esse tempo médio pelo número de pessoas que participaram do experimento, chegando assim no tempo de reação aos estímulos externos da sala. 
A escrita do relatório: aprendizagem e profissionalização em cursos técnicos...

Quadro 2 - Relatório de experimento após a primeira intervenção do professor

(R2) Nomes: MC, AAMC, AC

Turma: X

Relatório: Modos Normais de Vibração e Ressonância em cordas

Introdução e Objetivos

Quando dois corpos possuem a mesma frequência e estão conectados um com o outro, eles entram em ressonância, se um deles começar a vibrar. Ao possuir este conhecimento pode-se desenvolver estudos sobre fenômenos sonoros, pois os meios de telecomunicação usam da ressonância para seu funcionamento.

Com base nesses conhecimentos, foi feito um experimento em laboratório com o objetivo de:

- Calcular a que frequência um auto falante entra em ressonância com uma corda;

-Estabelecer uma relação entre a frequência do auto falante e o número de ventres (?) da corda quando esta estiver em ressonância com o aparelho;

Procedimentos e Métodos

Cada grupo tinha um gerador de sinais acoplado a um auto falante em suas mesas;

estes por sua vez estavam conectados a um fio de barbante, assim como na imagem:

\section{Desenho do procedimento}

No gerador de sinais há alguns botões que são usados para multiplicar a frequência emitida pelo gerador e um botão que varia a frequência emitida

02 desenhos do aparelho usado: um do botão que varia a frequência e outro do painel do aparelho. 
Primeiramente colocamos o gerador a uma frequência baixa e fomos aumentando-a até que a corda vibrasse. Entretanto, ao continuar a aumentar a frequência, a corda parou de vibrar. Continuamos a aumentar a frequência até chegar no dobro da primeira frequência em que a corda vibrou, mas desta vez a corda vibra com 2 ventres.

\section{Desenho dos ventres}

Colocou-se o triplo da primeira frequência, a corda fez 3 ventres, e assim por diante. Apresentação e Análise de Resultados

Tivemos uma margem, de erro entre as frequências obtidas. A corda vibrava entre $13 \mathrm{hz}$ e 18 hz, 30 hs e 35 hz, entre outros. Foi observado que as frequências obtidas eram múltiplas da primeira. Observou-se também que o número de ventres na corda era diretamente proporcional ao múltiplo da primeira frequência, entretanto está observação pode conter erros devido a faixa em que a frequência se encontrava (5

\section{$\mathrm{Hz}$. \\ Conclusão: Conclusão e considerações finais}

Conseguimos chegar aos nossos objetivos. A corda vibrava inicialmente a $15 \mathrm{~Hz}$ (média dos dados obtidos) e a cada vez que esta frequência era multiplicada aparecia um novo ventre na corda.

Uma análise preliminar desses dois relatórios mostra que as seções Introdução, Objetivos e Conclusão representam a maior dificuldade para os alunos. Nelas ocorrem os problemas relativos ao processo de transformação do pensamento em linguagem materializada; são nelas onde o processo de textualização é mais complexo, onde mais é acionada a competência discursiva dos aprendizes.

Os quadros 3, 4, 5 e 6 mostramos resultado da aplicação da proposta de Nascimento e Cristovão. 
A escrita do relatório: aprendizagem e profissionalização em cursos técnicos...

Quadro 3 - Constituição de uma base de orientação para adoção de RE.

\begin{tabular}{|l|l|l|}
\hline Aspectos analisados & $\begin{array}{l}\text { Relatório de } \\
\text { experimento } \\
\text { produzido sem a } \\
\text { intervenção do } \\
\text { professor R1 }\end{array}$ & $\begin{array}{l}\text { Relatório de } \\
\text { experimento produzido } \\
\text { com a intervenção do } \\
\text { professor R2 }\end{array}$ \\
\hline $\begin{array}{l}\text { O agente se } \\
\text { apresenta como } \\
\text { um sujeito que tem } \\
\text { identidade dentro } \\
\text { de um grupo? Trata- } \\
\text { se da realização de } \\
\text { uma tarefa escolar: a } \\
\text { produção/redação de } \\
\text { um texto? }\end{array}$ & $\begin{array}{l}\text { nome apenas, sem } \\
\text { anotar os nomes dos } \\
\text { colegas de grupo } \\
\text { com quem realizou o } \\
\text { experimento; realiza } \\
\text { a tarefa; trata-se de } \\
\text { um texto escolar e do } \\
\text { gênero relato. }\end{array}$ & $\begin{array}{l}\text { O aluno registra seu } \\
\text { nome e os nomes } \\
\text { dos colegas de grupo } \\
\text { com quem realizou o } \\
\text { experimento; realiza } \\
\text { a tarefa; trata-se de } \\
\text { um texto escolar, já } \\
\text { trazendo evidências de } \\
\text { um relatório. }\end{array}$ \\
\hline $\begin{array}{l}\text { O agente se apresenta } \\
\text { como um "técnico" na } \\
\text { atividade de realizar } \\
\text { um experimento de } \\
\text { laboratório (escolar)? }\end{array}$ & $\begin{array}{l}\text { Não exerce a função } \\
\text { de um técnico; apenas } \\
\text { se coloca como } \\
\text { estudante. }\end{array}$ & \\
\hline
\end{tabular}

Quadro 4-Operações de textualização: relações de ancoragem enunciativa implicada e autônoma; de referencialidade conjunta ou disjunta.

\begin{tabular}{|c|c|c|}
\hline Perguntas & R1 & $\mathrm{R} 2$ \\
\hline $\begin{array}{l}\text { Ancoragem enunciativa } \\
\text { implicada (eixo da } \\
\text { situação material) } \\
\text { A) O agente apresenta } \\
\text { lugar e tempo } \\
\text { imediatos? }\end{array}$ & $\begin{array}{l}\text { A) SIM. Apresenta lugar } \\
\text { social (sala = aula) e } \\
\text { tempo da realização } \\
\text { do experimento } \\
\text { (aula passada). } \\
\text { Obs.: O lugar físico } \\
\text { não é apresentado } \\
\text { (laboratório). }\end{array}$ & $\begin{array}{l}\text { A) } N A \tilde{O} \text {. Dá apenas a } \\
\text { informação de tempo } \\
\text { passado, exceto em } \\
\text { Introdução e objetivos } \\
\text { e indica o lugar físico } \\
\text { (laboratório). }\end{array}$ \\
\hline $\begin{array}{l}\text { O agente apresenta-se } \\
\text { como sujeito imediato? }\end{array}$ & $\begin{array}{l}\text { SIM/NÃO. Inclui-se em } \\
\text { um grupo de pessoas: } \\
\text { nós. }\end{array}$ & $\begin{array}{l}\text { Oscila, ao fazer uso da } \\
3^{a} \text { p. do sing. e da } 1^{\underline{a}} \text { p. } \\
\text { do pl. }\end{array}$ \\
\hline
\end{tabular}

Continua na página 186 
Continuação da página 185

\begin{tabular}{|c|c|c|}
\hline $\begin{array}{l}\text { Ancoragem enunciativa } \\
\text { autônoma (eixo da } \\
\text { situação material) } \\
\text { O agente faz apagamento } \\
\text { do } \\
\text { "eu"? }\end{array}$ & $\begin{array}{l}\text { SIM/NÃO. Aponta a } \\
\text { existência de pessoas } \\
\text { sem detalhar o seu } \\
\text { papel no grupo. }\end{array}$ & $\begin{array}{l}\text { SIM. Faz uso de } \\
\text { impessoalidade. }\end{array}$ \\
\hline $\begin{array}{l}\text { Ancoragem conjunta } \\
\text { (eixo de referencialidade) } \\
\text { O agente sobrepõe o } \\
\text { momento da realização } \\
\text { do experimento com o } \\
\text { da produção do texto: } \\
\text { um mundo (lugar, tempo } \\
\text { e atividade) presente ou } \\
\text { passado? }\end{array}$ & $N A \tilde{O} O$ & $N \tilde{A} O$ \\
\hline $\begin{array}{l}\text { Ancoragem disjunta (eixo } \\
\text { de referencialidade) } \\
\text { O agente separa o } \\
\text { momento da realização } \\
\text { do experimento com o } \\
\text { da produção do texto: } \\
\text { um mundo (lugar, tempo } \\
\text { e atividade) presente ou } \\
\text { passado? }\end{array}$ & $\begin{array}{l}\text { SIM. Apresenta/ } \\
\text { explicita o momento } \\
\text { preciso da realização } \\
\text { do experimento: } \\
\text { na aula passada; } \\
\text { apresenta a atividade; } \\
\text { deixa implícito o } \\
\text { lugar da realização do } \\
\text { experimento (outro } \\
\text { lugar diferente da sala } \\
\text { de aula - escola) }\end{array}$ & $\begin{array}{l}\text { SIM. Usa verbos no } \\
\text { passado; identifica } \\
\text { precariamente o lugar } \\
\text { (laboratório) }\end{array}$ \\
\hline
\end{tabular}


A escrita do relatório: aprendizagem e profissionalização em cursos técnicos...

Quadro 5 - Operações de textualização: operações de planificação/ adequação a um modelo de linguagem.

\begin{tabular}{|c|c|c|}
\hline $\begin{array}{l}\text { Aspectos analisados: } \\
\text { presença de elementos } \\
\text { do gênero relatório }\end{array}$ & $R 1$ & $\mathrm{R} 2$ \\
\hline $\begin{array}{l}\text { O aluno apresenta } \\
\text { um Cabeçalho com } \\
\text { identificação e título? }\end{array}$ & $\begin{array}{l}\text { Sim. Apresenta um } \\
\text { cabeçalho precário: } \\
\text { não menciona } \\
\text { os nomes dos } \\
\text { componentes do } \\
\text { grupo de laboratório, } \\
\text { da disciplina e do } \\
\text { professor Apresenta } \\
\text { título. }\end{array}$ & $\begin{array}{l}\text { Sim. Apresentaum } \\
\text { cabeçalho pouco } \\
\text { mais completo: } \\
\text { mencionaos nomes } \\
\text { dos componentes do } \\
\text { grupo de laboratório, } \\
\text { sem mencionar } \\
\text { a disciplina e o } \\
\text { professor Apresenta } \\
\text { título. }\end{array}$ \\
\hline $\begin{array}{l}\text { O aluno faz a seção } \\
\text { Introdução (resumo } \\
\text { teórico com indicação } \\
\text { do tema e sua } \\
\text { importância)? }\end{array}$ & $\begin{array}{l}N \tilde{A} O . \text { Apenas indica o } \\
\text { tema do experimento. }\end{array}$ & $\begin{array}{l}\text { SIM. Precariamente } \\
\text { menciona o tema } \\
\text { e deixa implícita a } \\
\text { importância. }\end{array}$ \\
\hline $\begin{array}{l}\text { O agente apresenta } \\
\text { a seção Objetivos } \\
\text { (previsão de } \\
\text { resultados a serem } \\
\text { alcançados ou que } \\
\text { deveriam alcançados)? } \\
\text { Menciona objetivo } \\
\text { geral e específico? }\end{array}$ & $\begin{array}{l}\text { Não. Apenas } \\
\text { indiretamente: o } \\
\text { objetivo mencionado } \\
\text { é um objetivo } \\
\text { escolar(estudar); não } \\
\text { faz menção. }\end{array}$ & $\begin{array}{l}\text { SIM. Apresenta } \\
\text { dois objetivos; não } \\
\text { menciona qual seria } \\
\text { o objetivo geral e } \\
\text { qual seria o objetivo } \\
\text { específico. }\end{array}$ \\
\hline $\begin{array}{l}\text { O agente apresenta } \\
\text { Procedimentos e } \\
\text { Métodos (descrição } \\
\text { das ações realizadas } \\
\text { para alcançar o } \\
\text { objetivo)? }\end{array}$ & $\begin{array}{l}\text { SIM. Descreve } \\
\text { o experimento } \\
\text { realizado. }\end{array}$ & $\begin{array}{l}\text { SIM. Descreve } \\
\text { o experimento } \\
\text { realizado. }\end{array}$ \\
\hline
\end{tabular}




\begin{tabular}{|c|c|c|}
\hline & & Continuaçāo da página \\
\hline $\begin{array}{l}\text { O agente faz } \\
\text { Apresentação e } \\
\text { Análise dos dados } \\
\text { obtidos? Apresenta } \\
\text { os resultados } \\
\text { (informações sobre } \\
\text { os fenômenos ou } \\
\text { conceitos que podem } \\
\text { ser interpretados a } \\
\text { partir dos dados)? } \\
\text { Os fenômenos } \\
\text { ou conceitos } \\
\text { apresentados na } \\
\text { Introdução podem } \\
\text { ser vistos através dos } \\
\text { resultados? }\end{array}$ & $\begin{array}{l}\text { Não. Deixa-os } \\
\text { implícitos. }\end{array}$ & $\begin{array}{l}\text { SIM. Precariamente. } \\
\text { Apresenta os } \\
\text { resultados, mas não } \\
\text { os analisa. }\end{array}$ \\
\hline $\begin{array}{l}\text { O agente apresenta } \\
\text { Conclusão: (retomada } \\
\text { dos objetivos do } \\
\text { experimento? Analisa } \\
\text { os resultados? Avalia } \\
\text { a qualidade dos } \\
\text { resultados? Aplica os } \\
\text { resultados ao tema } \\
\text { de estudo/lista ou } \\
\text { conteúdo do roteiro } \\
\text { de perguntas? Faz } \\
\text { ligação do tema com a } \\
\text { realidade cotidiana das } \\
\text { pessoas?) }\end{array}$ & SIM. Precariamente: & $\begin{array}{l}\text { SIM. Retoma os } \\
\text { objetivos e "chegando } \\
\text { assim no tempo } \\
\text { resultados; não } \\
\text { analisa e faz de reação } \\
\text { "; não analisa os } \\
\text { resultados; avaliação } \\
\text { na seção anterior; } \\
\text { resultados; não avalia } \\
\text { a reação; não associa } \\
\text { o tema à qualidade } \\
\text { dos resultados; não } \\
\text { os aplica ao cotidiano } \\
\text { das pessoas. não faz } \\
\text { ligação do tema com o } \\
\text { cotidiano das pessoas. }\end{array}$ \\
\hline
\end{tabular}


Quadro 6 - Operações de textualização: operações de constituição de estratégias linguísticas e discursivas

\begin{tabular}{|c|c|c|}
\hline $\begin{array}{l}\text { Estratégias } \\
\text { analisadas }\end{array}$ & $\mathrm{R} 1$ & R2 \\
\hline Conexão & $\begin{array}{l}\text { Expressão temporal: "Na } \\
\text { aula passada" } \\
\text { Expressão de lugar: "sala" } \\
\text { Expressão de modo/ } \\
\text { conclusão: } \\
\text { "assim" } \\
\text { Expressão de finalidade: } \\
\text { "para" } \\
\text { Expressão de causa: } \\
\text { "Como" } \\
\text { Expressão de adição:"e" }\end{array}$ & $\begin{array}{l}\text { Expressão temporal: "Na } \\
\text { aula passada", "inicialmente" } \\
\text { Expressão de lugar: "sala" } \\
\text { Expressão de modo/ } \\
\text { conclusão: } \\
\text { "assim"; "diretamente" } \\
\text { Expressão de finalidade: } \\
\text { "para" } \\
\text { Expressão de causa: "pois" } \\
\text { Expressão de adição:"e" } \\
\text { Expressão de ressalva: } \\
\text { "entretanto" }\end{array}$ \\
\hline $\begin{array}{l}\text { Coesão } \\
\text { nominal e } \\
\text { verbal }\end{array}$ & $\begin{array}{l}\text { Elipse de sujeito: } \\
\text { estudamos, fizemos... } \\
\text { Ruptura de tempo verbal: } \\
\text { "dará" } \\
\text { Ausência de sujeito: } \\
\text { "Como em sempre dará o } \\
\text { mesmo resultado" }\end{array}$ & $\begin{array}{l}\text { Elipse de sujeito: colocamos, } \\
\text { fomos, continuamos } \\
\text { Ruptura de tempo } \\
\text { verbal: passado/presente } \\
\text { (Procedimentos e Métodos) }\end{array}$ \\
\hline $\begin{array}{l}\text { Vozes e } \\
\text { Modalização }\end{array}$ & Ausência de ambas. & $\begin{array}{l}\text { Vozes: não } \\
\text { Modalização: sim "pode-se } \\
\text { desenvolver"; "pode conter" }\end{array}$ \\
\hline
\end{tabular}

Na constituição de uma base de orientação, a partir do aluno, ao produzir R1 omitindo a informação de que o experimento tinha sido feito coletivamente, pode-se inferir que, naquele momento, ele estaria isolando o escrever (o relatório) do fazer (o experimento). Será que para ele mencionar os nomes dos colegas não tem importância? Será que o experimento foi feito em grupo apenas por motivos logísticos? Para ele, a participação dos colegas na realização do experimento não tem valor? São algumas questões que podem ser levantadas a partir do desempenho do aluno no primeiro dia de aula, apenas com seus conhecimentos prévios sobre o gênero. Em R2, o aluno, além de registrar a participação 


\section{Léa Dutra Costa}

dos membros do grupo, citando seus nomes no cabeçalho, evidencia a transformação de R1 em R2. A atividade parece permanecer como uma atividade escolar, embora não tenha feito mais referência ao meio social, à aula, o que pode indicar alguma mudança no posicionamento do aluno em relação à atividade.

Com relação às operações de ancoragem enunciativa implicada e autônoma, conjunta e disjunta, pode-se afirmar que são mais precárias em R1 do que em R2. Ao não mencionar o lugar e o tempo de forma implicada, o aluno sinaliza que relativizou a importância dessas informações, aproximando-se mais das características genéricas de um relatório de experimento e afastando-se do gênero relato. 0 mesmo pode indicar a oscilação entre a $3^{\underline{a}}$ e $1^{\underline{a}}$ pessoa que o coloca como sujeito imediato da atividade. A ancoragem conjunta e disjunta, apesar de precária, apresenta alguma evolução em R2. Sobressai, no eixo da situação material, a oscilação entre as pessoas do discurso, o que evidencia a problemática da questão do sujeito (autoria) e do fato de ser gênero escolarizado tanto em R1 quanto em R2. 0 aluno passa a fazer, em R2, operações de planificação, fazendo-as, contudo, de forma precária. Ele apresenta, em um mesmo espaço, elementos de uma Introdução a Objetivos, sem distingui-los; apresenta resultados, retoma objetivo, mas não os analisa nem os associa ao cotidiano das pessoas.

As operações de planificação associadas à Introdução, Análise de Resultados e Conclusão parecem apresentar mais dificuldade do que as operações ligadas às demais seções. Observa-se nitidamente o aumento das expressões de conexão, mas a ruptura de tempo verbal, que ocorre em R1 permanece em R2. Apesar de em R2 ainda não serem apresentadas vozes, surgem poucas marcas de modalização. Seria, portanto, pertinente pensar que o aluno agente estaria se apropriando de pelo menos um desses recursos de linguagem importante da elaboração das seções Introdução e Análise de Resultados em especial.

\section{Considerações finais}

Os resultados analisados revelam que, pedagógica e linguisticamente, a apropriação do instrumento de aprendizagem - o relatório, neste estudo - depende dos conhecimentos prévios do aluno, da sua capacidade de trabalhar a competência discursiva bem como das intervenções do pro- 
fessor, sem a exigência da aplicação de uma sequência didática, até mesmo porque pode haver uma lacuna na formação acadêmica do docente em ciências no que diz respeito à escrita e aos gêneros textuais.

Pelas mesmas razões, pode-se inferir que há bons indicadores para que a escrita de relatórios de experimento, como uma prática discursiva, direta e intensamente envolvida na formação de técnicos de nível médio, venha a se revelar uma ferramenta de aprendizagem pouco segura, diante de certa incompatibilidade natural entre o referido gênero e a fase de desenvolvimento humano em que se encontra o aluno: a adolescência. Se o olhar se volta para o futuro do aluno tanto na graduação quanto no trabalho pode-se vislumbrar um resultado positivo, uma vez que ele estará de posse de um conhecimento que seus professores esperam que ele tenha, de uma atividade bastante demandada que caracteriza o domínio da linguagem de uma esfera social.

Ao se voltar o olhar para o presente do aluno, o efeito de sentido que o emprego de um gênero como esse tem sobre um adolescente e sua formação acadêmica poderia implicar um efeito contrário: um "descaminho" para o futuro, não só por ser uma atividade repetitiva e cansativa (conforme dados de entrevistas com alunos), mas também por ser uma atividade que exige domínio da escrita, o que nem todos trazem do ensino fundamental e o que, como esperado, lhes será um grande desafio.

\section{Referências}

ANTUNES, I. Aula de português: encontro e interação. São Paulo: Parábola, 2010.

BAKHTIN, M. Os gêneros do discurso. In: Estética da criação verbal. São Paulo: Martins fontes, 2003.

BALTAR, M. A validade do conceito de competência discursiva no ensino de língua materna. Revista Linguagem em (Dis)curso. L em D, Tubarão, v.5, n.1, (PDF), jul/ dez, 2004. Disponível em: <http://www.portaldeperiodicos.unisul.br/index.php/ Linguagem_Discurso/article/view/308/324>. Acesso em: 2 de maio 2015.

BAWARSHI, A. S; REIFF, M. J. Gênero: história, teoria, pesquisa, ensino. Tradução de Benedito Gomes Bezerra. São Paulo: Parábola, 2013, 285p.

BAZERMAN, C. Gêneros textuais, tipificação e interação. São Paulo: Cortez, 2005.

BRASIL. Lei de Diretrizes e Bases no 9.394, de 20 de dezembro de 1996. Estabelece as diretrizes e bases da educação nacional. Disponível em: <http://portal.mec.gov. br/arquivos/pdf/ldb.pdf >. Acesso em: 10 de maio 2015. 


\section{Léa Dutra Costa}

BRONCKART, J. Atividades de linguagem, textos e discursos: Por um interacionismo sócio-discursivo. São Paulo: EDUC, 2003.

COSTA, L. D; LIMA, Fabíola de O. Perspectiva discente sobre baixo rendimento escolar em matemática na primeira série do ensino médio profissional. In: SIMPÓSIO NACIONAL DE ENSINO DE CIÊNCIAS E TECNOLOGIA, 2, 2010, Ponta Grossa. Anais Ponta Grossa: Revista Brasileira de Ensino de Ciência e Tecnologia, do Programa de Pós-Graduação em Ensino de Ciência e Tecnologia da Universidade Tecnológica Federal do Paraná - PPGECT/UTFPR, Artigo 48. Disponível em: http://www.sinect.com.br/anais2010/artigos/EM/48.pdf>. Acesso em 10 de maio 2015.

CRISTÓVÃO, V. L. L; NASCIMENTO, E. L. Gêneros textuais e ensino: contribuições do interacionismo sócio-discursivo. In: KARWOSKI, A. M.; GAYDECZKA, B.; BRITO, K. S. (Org.). Gêneros textuais: reflexões e ensino. 4ed. São Paulo: Parábola Editorial, 2011, 198p.

FERNÁNDEZ, A. A inteligência aprisionada. Porto Alegre: ArtMed, 1991.

GREGORIO, N. B. Leitura e produção escrita do gênero relatório para desenvolvimento de habilidades. Revistas, 2005. Disponível em: <pucspbr/índex.php/intercambio/article/view/3948>. Acesso em: 12 de maio 2010.

KARWOSKY, A. M; GAYDECZA, B; BRITO, K. S. (Org.). Gêneros textuais: reflexões e ensino. 3ed. Rio de Janeiro: Editora Lucerna.

KLEIN, B; ALLER, B. M. Writing Across the curriculum in college chemistry: A practical bibliography. Language and Learning Across the Disciplines v.2, n.3: April 2535, 1998 apud Souza e Arroio, 2009).

KNOBEL, M. Adolescência e sexualidade. Março 2007. Entrevista concedida à revista Health \& Manegement. Disponível em www.cepps.com.br/item23593.asp. Acesso em maio 2010.

PAIN, S. Diagnóstico e tratamento dos problemas de aprendizagem. Porto Alegre: Artmed, 1992.

SCHNEUWLY. B; DOLZ, J. Gêneros orais e escritos na escola. Trad. e org. de Roxane Rojo e Glaís Sales Cordeiro. Campinas: Mercado de Letras, 2004.

SILVA, R. W. Escrita do gênero relatório de estágio supervisonado na formação inicial do professor brasileiro In: Revista Brasileira de Linguística Aplicada, v.13, n.1, 2013, Belo Horizonte, Faculdade de Letras.

SOARES, Magda B. Linguagem e escola - uma perspectiva social. São Paulo: Ática, 1986.

SOUZA, D. D; ARROIO, A. A questão da escrita, forma e conteúdo, mediada por gênero do discurso escolar-científico nas aulas de Química. VII ENPEC. Florianópolis, 8 de Nov. 2009. Disponível em posgrad.fae.ufmg.br/posgrad/viienpec/pdfs/643. Acesso em jul. 2010. 